\title{
A 5-year evaluation of the emergency contraception enhanced community pharmacy service provided in Wales
}

\author{
Efi Mantzourani (D) , ${ }^{1}$ Karen Hodson, ${ }^{1}$ Andrew Evans, ${ }^{2}$ Sarah Alzetani, ${ }^{1}$ \\ Rebecca Hayward, ${ }^{1}$ Rhian Deslandes, ${ }^{1}$ Mary Louise Hughes, ${ }^{1}$ \\ Gareth Holyfield, ${ }^{3}$ Cheryl Way ${ }^{4}$
}

\begin{abstract}
- Additional material is published online only. To view please visit the journal online (http://dx.doi.org/10.1136/ bmjsrh-2018-200236).

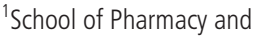
Pharmaceutical Sciences, Cardiff University, Cardiff, UK ${ }^{2}$ Llywodraeth Cymru, Cardiff, UK ${ }^{3}$ Public Health Wales, Cardiff, UK ${ }^{4}$ National Health Service Wales Informatics Service, Cardiff, UK
\end{abstract}

\section{Correspondence to}

Dr Efi Mantzourani, School of Pharmacy and Pharmaceutical Sciences, Cardiff University, Cardiff, South Glamorgan CF10 3AT, UK; MantzouraniE1@cardiff. ac.uk

Received 25 September 2018 Revised 3 July 2019

Accepted 21 July 2019 Published Online First 8 August 2019

\section{A Check for updates}

(c) Author(s) (or their employer(s)) 2019. No commercial re-use. See rights and permissions. Published by BMJ.

To cite: Mantzourani E, Hodson K, Evans A, et al. BMJ Sex Reprod Health

2019:45:275-282.

\begin{abstract}
Background Access to emergency contraception (EC) has been a core component of attempts to address high teenage pregnancy rates in Wales. A national service was commissioned in 2011, allowing supply of EC free of charge from community pharmacies (CPs). This study investigated 5 years of the EC service, to describe its use and investigate changes in the pattern of use over time.
\end{abstract}

Methods Secondary analyses of data from all National Health Service funded CP EC consultations in Wales between 1 August 2012 and 31 July 2017 ( $n=181$ 359). Data comprised standardised clinical and demographic information, in the form of predefined service user responses, submitted for reimbursement by CPs.

Results Overall service provision remained relatively consistent over the study period, with women aged between 13 and 59 years accessing the service. An association was observed between the time since unprotected sexual intercourse and the day on which the service was accessed $\left(X^{2}(18)=16292.327, p<0.001\right)$. Almost half (47.9\%) of requests were because no contraception had been used, with a strong and positive association for teenagers and women aged $40+$ years. A statistically significant and increasing percentage of consultations were accompanied by further sexual health advice $(r=0.7, p<0.01)$.

Conclusions Access to EC through CPs is contributing to reducing teenage conceptions and termination rates. However, action is needed to increase contraception use in all age groups. Reduced availability of CP services on Sundays is a barrier to timely EC access. Findings support an expanded role for community pharmacists in provision of regular contraception.

\section{Key messages}

- The community pharmacy emergency contraception (EC) service helps meet the EC needs of women of any age, despite originally being targeted at teenagers.

- The reasons for attending an EC consultation vary with age, and agetargeted actions are needed to increase awareness of contraception use in all age groups.

- Results support expansion of the role of the community pharmacists to include provision of regular contraception.

\section{INTRODUCTION}

Emergency contraception (EC) is used to prevent pregnancy following unprotected sexual intercourse (UPSI) or contraceptive failure. In the UK, two methods of EC are in common use: insertion of an intrauterine device (IUD) within 5 days of UPSI; and the administration of an emergency contraceptive pill. ${ }^{1}$ Two types of licensed EC pill are currently available. Preparations containing levonorgestrel (LNG), licensed for use up to 72 hours following UPSI, have been available since 2000, whereas the ulipristal acetate (UPA) 30 mg tablet (EllaOne), for use within 120 hours of UPSI, has been available since $2009 .^{2} 3$ Initially EC pills were licensed in the UK as prescription-only medicines (POMs), requiring a prescription from general practitioners (GPs), or supplied by family planning or accident and emergency services.

In the early 2000s, in an attempt to improve access to EC, National Health 
Data from all NHS funded Emergency Contraception (EC) consultations taking place in

Community Pharmacies (CPs) in Wales between 1 August 2012 and 31 July 2017 were

obtained from the NHS Wales Shared Services Partnership from details of EC service

consultations, submitted by CPs for reimbursement. Data contained standardised clinical

and demographic information, in the form of pre-defined responses recorded by pharmacists, in the format of Microsoft Excel(8) database.

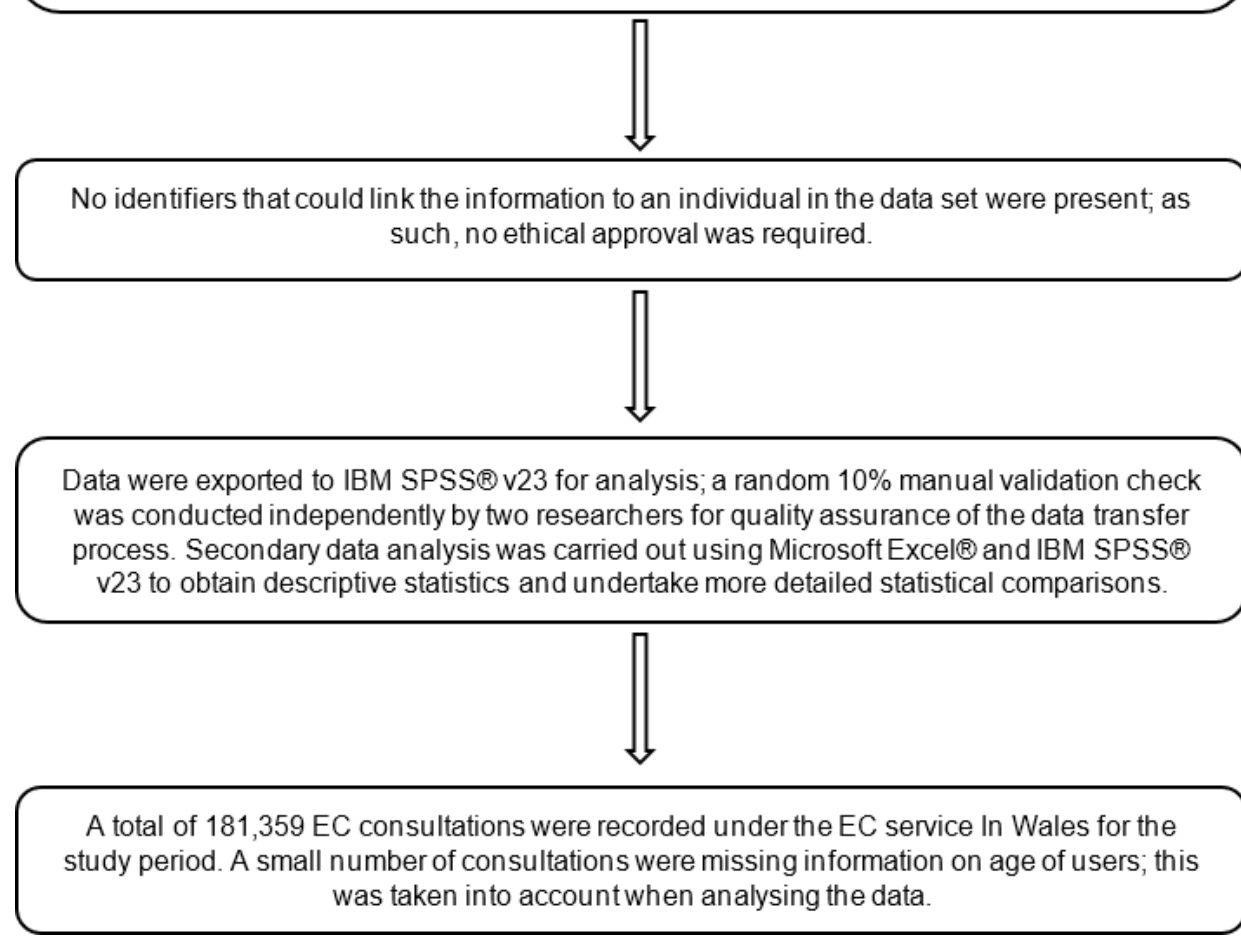

Figure 1 A flowchart illustrating the study methodology, in accordance with RECORD guidelines. CP, community pharmacy; EC, emergency contraception; NHS, National Health Service. ${ }^{13}$

Service (NHS) bodies across the UK, began making provision for POM LNG to be supplied from community pharmacies (CPs) without prescription using patient group directions (PGDs). ${ }^{4}$ Subsequently, LNG was reclassified as a pharmacy medicine, to allow it to be sold 'over-the-counter' (OTC) from CPs. However, the high cost of OTC relative to POM preparations, and licensing restrictions which prevented pharmacists selling EC to girls aged $<16$ years, remained barriers to wider access and NHS-funded PGD schemes persisted. ${ }^{5}$

In 2011, the Welsh Government directed local health boards to commission a national EC service from CPs allowing LNG to be obtained by women and girls from the age of 13 years free of charge under a PGD. ${ }^{6}$ In April 2015, the service was extended to allow UPA to be supplied between 72 and 120 hours after UPSI. The arrangements aimed to widen access to EC and increase the provision of sexual health advice among sexually active women. By $2017,76 \%$ of CPs in Wales (544/716) were providing the service. ${ }^{7}$

Most previous research has focused on OTC sales of EC, rather than supply under a PGD. ${ }^{8-12}$ In general, studies have been small-scale evaluations of pilot schemes that have, however, consistently identified that pharmacy services promote access to EC and are highly acceptable to service users, with many reporting CPs as the preferred route of access. There has to date been no large-scale, longitudinal evaluation of EC provision by CPs to explore whether the benefits identified in smaller studies are maintained over time. The aim of this study was two-fold: first to describe the CP EC use in Wales between 2012 and 2017 and and second to investigate changes in the pattern of EC use over time.

\section{METHODS}

Figure 1 presents an overview of the study methodology. ${ }^{13}$

\section{Study design and setting}

Secondary analyses of data from all NHS-funded EC consultations taking place in CPs in Wales between 1 August 2012 and 31 July $2017(n=181$ 359) was undertaken. Data were obtained from the NHS Wales Shared Services Partnership from details of EC service consultations, submitted by CPs for reimbursement. Data contained standardised clinical and demographic information, in the form of predefined responses recorded by pharmacists.

As there were no identifiers that could link the information to an individual in the dataset, this study required no ethical approval. ${ }^{14}$ 


\section{Measures}

Our primary outcome was the number of CP EC consultations over time. Secondary outcomes were consultation outcome (ie, EC supplied or not, LNG vs UPA); the rate of EC use by age group; EC access by day of week; time since UPSI; reason for requesting EC and regular use of contraception by service users, defined in the service specification as the use of any form of prescribed contraception including oral contraception, contraceptive patch, long-acting reversible contraception, or IUD or intrauterine system; and how these changed over time.

\section{Statistical analyses}

Data were exported to IBM SPSS v23 for analysis; a random 10\% manual validation check was conducted independently by two researchers for quality assurance of the data transfer process. No discrepancies were identified. Secondary data analysis was carried out using Microsoft Excel and IBM SPSS v23 to obtain descriptive statistics and undertake more detailed statistical comparisons. Scatter plots and line graphs with 95\% confidence intervals were used to assess linearity between time and EC service use as well as outcomes. Pearson's chi-squared $\left(\chi^{2}\right)$ tests were used to determine if there were any statistically significant associations between variables $(p<0.05)$, and the distribution of standardised residuals (z-scores) to determine the strength of the associations.

\section{Patient involvement}

Patients were not involved in the design or conduct of this study.

\section{RESULTS}

Overall characteristics of the population using the EC service for all 181359 recorded consultations between 1 August 2012 and 31 July 2017 are presented in table 1 . There was evidence of a decline in the absolute number of EC requests over the study period $(\mathrm{r}=-0.41, \mathrm{p}=0.001)$ (online supplementary figure 1$)$. The median age of service users was 25 (range 13-59, IQR 19-30) years (data available for $n=175460$ consultations). After age data were standardised per age group population using data for estimated population in Wales, ${ }^{15}$ the highest rate of consultations was noted for 16-19-year-olds (at 5.5 consultations per 100 population) (table 2 ).

\section{Day and time after UPSI EC service was accessed}

There was a statistically significant difference in the number of consultations with day of week (KruskalWallis test, $\mathrm{p}<0.001,95 \% \mathrm{CI})$. More than a quarter of the consultations were conducted on a Monday $(25.8 \%)$ and just under a quarter of consultations $(24.6 \%)$ during the weekend (figure 2). An association was observed between the time since UPSI and the day on which the service was accessed
$\left(\mathrm{X}^{2}(18)=16 \quad 292.327, \quad \mathrm{p}<0.001\right) . \quad$ Consultations within 25-48 hours of UPSI were more likely to happen on Mondays and Tuesdays, and for 49-120 hours since UPSI on Mondays, Tuesdays and Wednesdays (online supplementary table 1 ). In the 5-year period, more than two-thirds of requests made through the EC service took place within 24 hours of UPSI (67.5\%). Requests made more than 49 hours after UPSI increased from $6.0 \%$ to $10.5 \%$ of the total annual consultations.

\section{Reasons for requesting EC}

Over the 5 -year period, almost half (47.9\%) of requests made through the EC service were because no contraception had been used. EC requests resulting from barrier contraception failure decreased from $45.8 \%$ to $37.9 \%$ over the study period (table 1 ), $\mathrm{p}$ value for trend 0.002 (figure 3 ). A statistically significant association was found between $\mathrm{EC}$ request reasons and the age group of EC service users $\left(X^{2}(15)=989.271\right.$, $\mathrm{p}<0.001)$. There was a strong negative association between EC requests due to barrier contraception failure and patients aged $\leq 24$ years, and a strong positive association for those aged $>25$ years. A strong positive association was observed for no contraception use and teenagers, and reporting of missed contraceptive pills and women aged between 20 and 29 years (online supplementary table 2).

\section{Regular contraception use}

Over the 5 years, the percentage of consultations conducted with patients who used regular contraception decreased from $44.2 \%$ to $33.9 \%$ (table 1 ), $\mathrm{p}$ value for trend $<0.001$ (online supplementary figure 3 ). A statistically significant association was found between regular contraception use and the age group of EC service users $\left({ }^{2}(5)=724.655, \mathrm{p}<0.001\right)$. Teenagers and women aged $40+$ years were more likely to not use regular contraception (online supplementary table 3 ).

\section{Service outcomes}

LNG was supplied in $96.7 \%$ of the consultations; $2.4 \%$ of consultations resulted in no medication being supplied (table 1). Since 2015, LNG and UPA were supplied in $95.8 \%$ and $2.2 \%$ of consultations, respectively. The proportion of UPA supplies was similar to the rate of late presentations $(2.2 \%$ and $1.5 \%$, respectively). Only $0.1 \%$ of users $(n=187)$ failed to access the service within 120 hours following UPSI. No data were available to identify reasons for delayed access.

Further sexual health and contraception counselling was provided in $79.2 \%$ and referral to another agency in $31.3 \%$ of EC consultations; both increased with time (Pearson's correlation $\mathrm{r}=0.7, \mathrm{p}<0.001$ and $\mathrm{r}=0.56, \mathrm{p}=0.002$, respectively, online supplementary figure 4 and 5). 


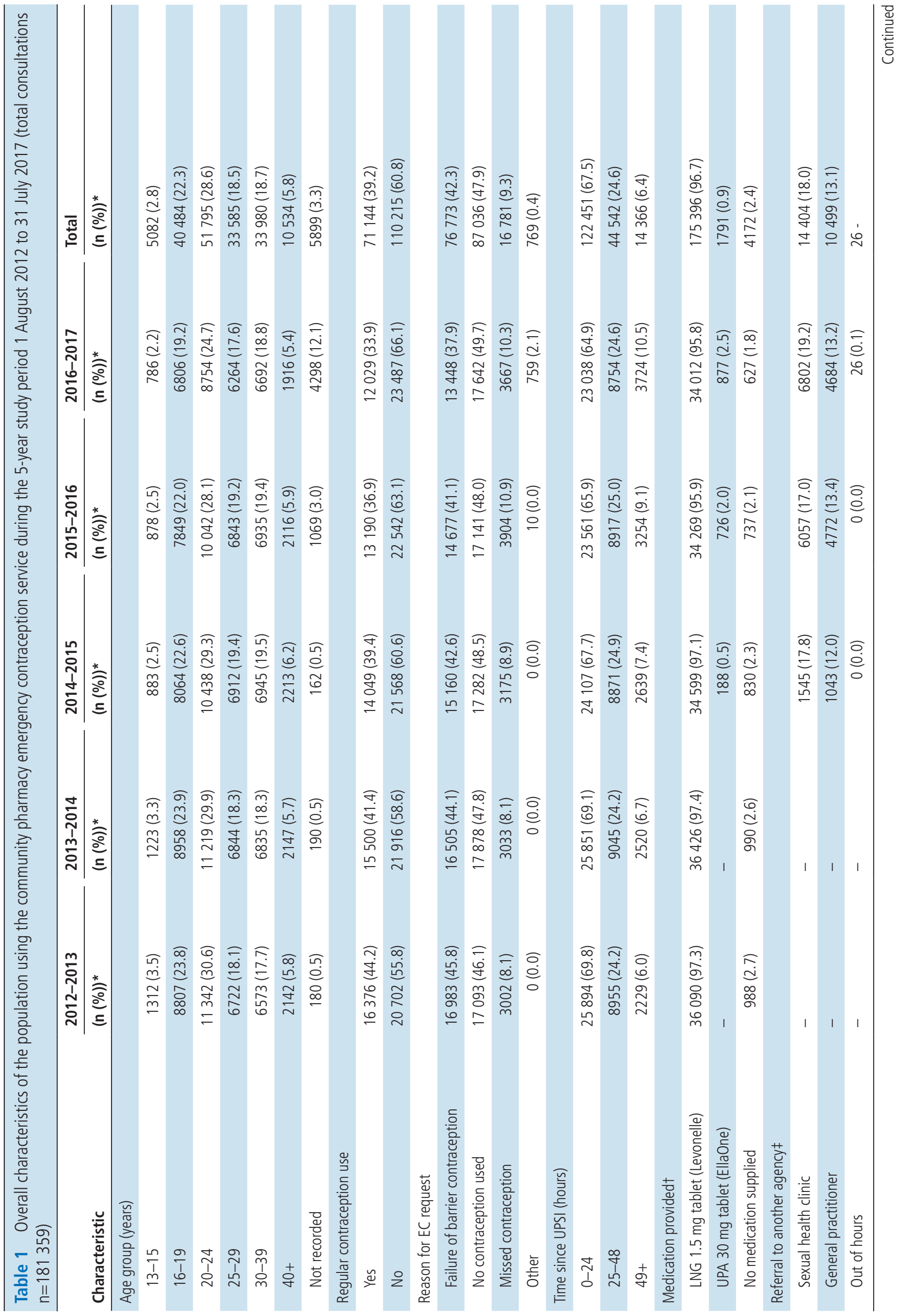




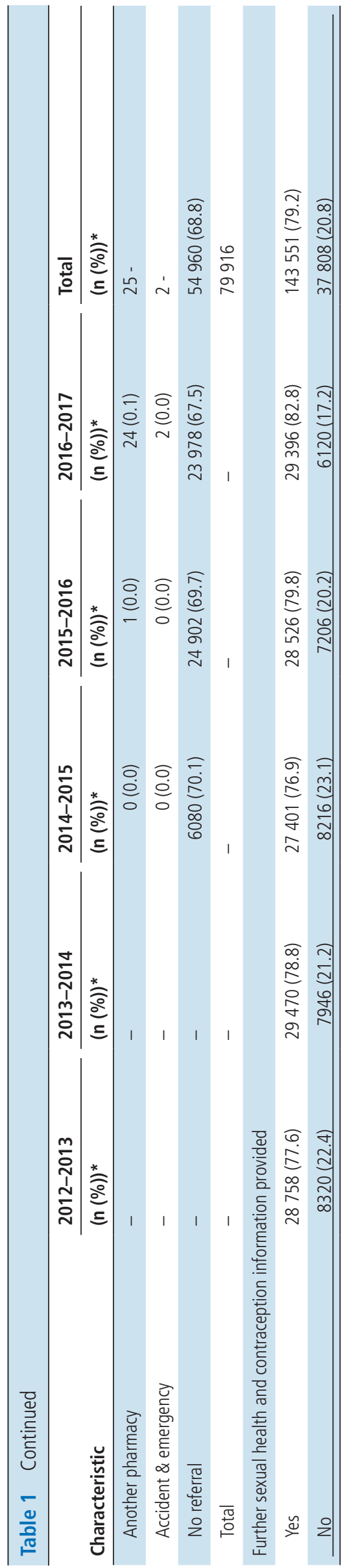

Table 2 Rate of consultations per age group, when numbers were standardised using data for estimated population in Wales ${ }^{15}$ (data available for 2012-2016)

\begin{tabular}{llcl}
\hline $\begin{array}{l}\text { Age group } \\
\text { (years) }\end{array}$ & $\begin{array}{l}\text { Average } \\
\text { population }(\mathrm{n})\end{array}$ & $\begin{array}{l}\text { Average number } \\
\text { of users per } \\
\text { year }(\mathbf{n})\end{array}$ & $\begin{array}{l}\text { Rate } \\
\text { (users/100 } \\
\text { population) }\end{array}$ \\
\hline $13-15$ & 103855 & 1074 & 1.0 \\
\hline $16-19$ & 153323 & 8420 & 5.5 \\
\hline $20-24$ & 211100 & 10760 & 5.1 \\
\hline $25-29$ & 200900 & 6830 & 3.4 \\
\hline $30-39$ & 358000 & 6822 & 1.9 \\
\hline $40+$ & 818100 & 2155 & 0.3 \\
\hline
\end{tabular}

\section{DISCUSSION}

This study describes long-term trends in the use of CP EC services using data from all NHS-funded EC consultations in CPs in Wales over a 5 -year period, and provides the first insight into the changing pattern of CP EC service use over time. We found substantial numbers of EC consultations took place in CPs in each year of the study but with indications that numbers of consultations were declining over time. By the end of Year 5, the annual number of consultations was $4.2 \%$ lower than at the end of Year 1. However, data indicate the decline took place between Years 2 and 3 with little change in consultation numbers in the most recent 3-year period. Previous studies report concern of an increasing demand for EC when introducing a $\mathrm{PGD} ;{ }^{11}$ we found no evidence to support concerns that routine access to EC from CP leads to increased use over time. Over $97 \%$ of consultations resulted in the supply of EC. A small reduction in the proportion of consultations resulting in supply of LNG was observed following the inclusion of UPA, as a treatment option for service users presenting more than 72 hours following UPSI, in April 2015.

Most EC consultations took place with 20-24-yearolds; however, use in this group represented less than $30 \%$ of all EC consultations, with the service accessed by large numbers of service users of all ages. This suggests the service is helping meet the sexual health needs of many women regardless of age. Despite a lower number and proportion of consultations among 16-19-year-olds, age-standardised rates demonstrate this group were the most frequent users of the $\mathrm{CP}$ service over the study period. This finding supports the role of the CP EC service as part of a wider teenage pregnancy strategy. Access to free-of-charge EC, which is especially relevant to young users, may have contributed to uptake. ${ }^{10}$ Despite use being high in teenagers aged $16-19$ years, in teenagers aged $13-15$ years it was very low; this must be interpreted carefully as age may have been deliberately concealed due to negative societal perceptions of sexual intercourse in those under the legal age of consent. 
Percentage (\%) of Consultations for the Time After UPSI on Each Day of the

Week

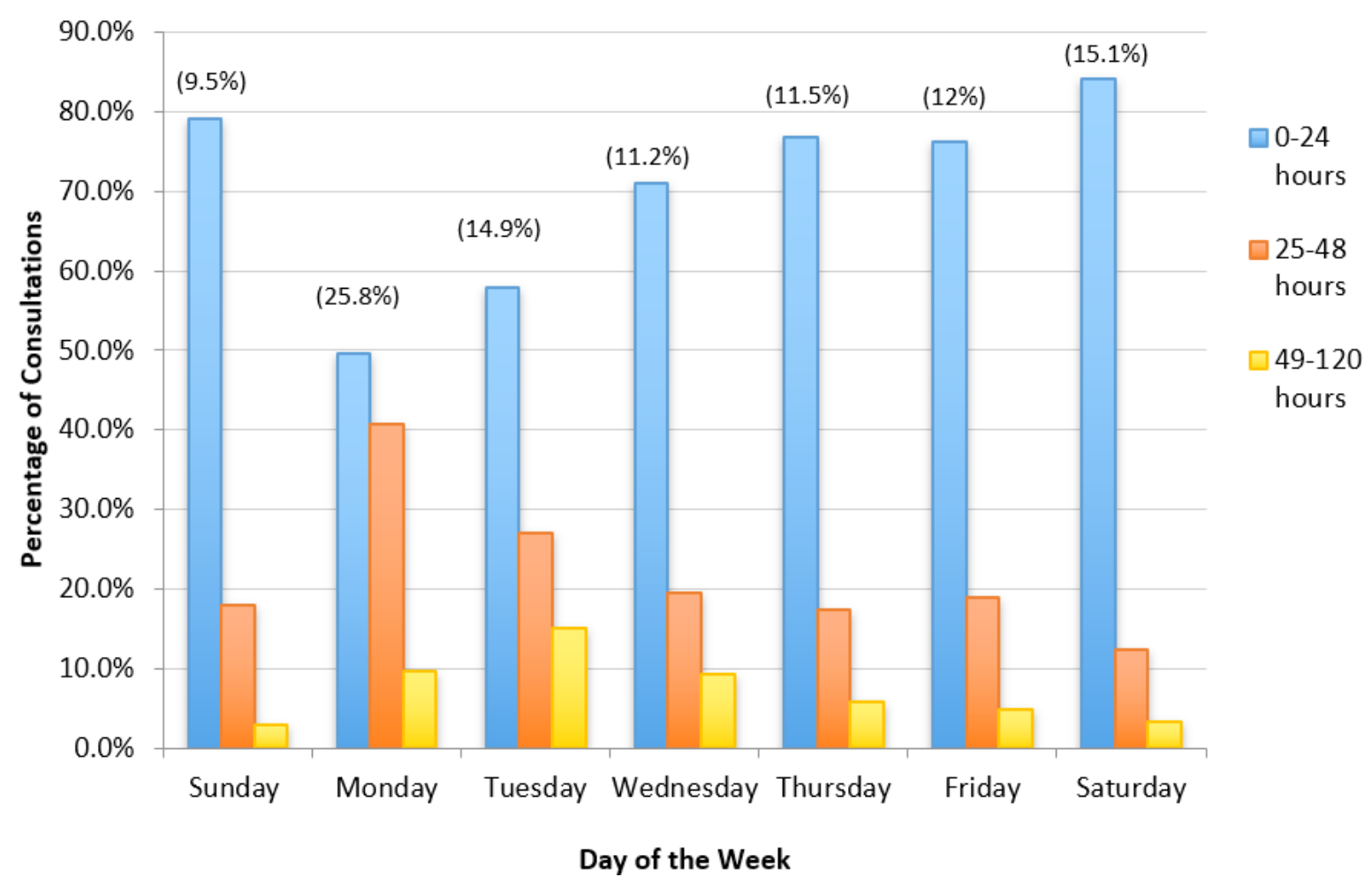

Figure 2 Graph illustrating the percentage (\%) of consultations that took place within the stated time frames after unprotected sexual intercourse (UPSI) for each day of the week (information available for $n=181$ 172). The proportion of consultations for the different days of the week is given in parentheses.

Access to EC from CPs has coincided with decreased rates of abortion ${ }^{16}$ and live births to teenage mothers in Wales. ${ }^{17}$ While the rate of abortions in the 20-24-year-old age group has decreased, ${ }^{16}$ it remains higher than in other age groups, following the same pattern as the number of EC consultations during the study period. This may suggest this group who would have been teenagers at the start of the study period and were the target of measures to improve availability of EC, continue to use EC as a means

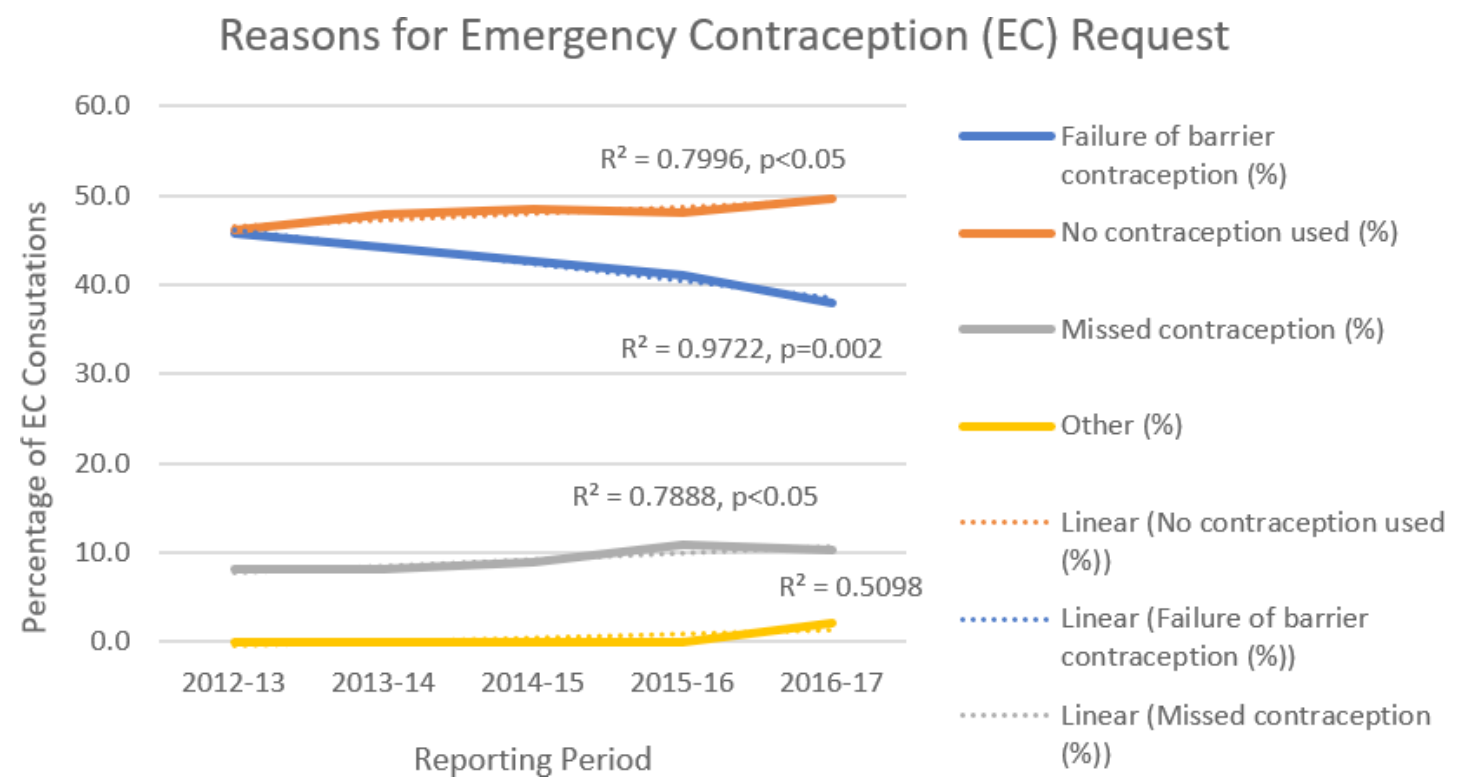

Figure 3 Graph illustrating the percentage of consultations for the different reasons emergency contraception (EC) was requested, per reporting period (information available for $n=181359$ ). P values for trend lines have been calculated with $95 \%$ confidence intervals. 
of contraception in later life. Further work may be required to promote routine contraception among this age group.

Around 25\% of all EC consultations occurred on a Monday, with Tuesday and Saturday (at $\sim 15 \%$ ) the next most popular days. The lowest proportion of consultations was observed on Sunday (9.5\%). This, alongside the finding that girls and women using the CP EC service on Monday, Tuesday and Wednesday were more likely to have had UPSI more than 48 hours earlier, suggest poorer access to EC over the weekend. Prompt access is of clinical significance, as the sooner EC is taken the more effective it is. ${ }^{1}$ Previous studies found that access was a barrier to EC use and that the longer opening hours, weekend openings and more accessible locations of pharmacies allowed most users to access EC within 24 hours; ${ }^{9} 121819$ our study demonstrates that there remain barriers to access on Sunday. Possible reasons for this are fewer pharmacies being open and shorter opening times among those pharmacies that are open. A focused review of accessibility of EC service on Sunday would be beneficial for service commissioners, to explore whether other determinants, for example the absence of a pharmacist accredited to provide the EC service, contributed to this finding.

The reasons for requesting EC differ with age. Women aged $<19$ years and $40+$ years were more likely not to use regular contraception, although we found differences between these groups in relation to UPSI. In general, those aged $<19$ years were more likely to report not using any form of contraception; those $40+$ years of age were more likely to report failure of barrier contraception. Our data indicate women aged 20-29 years were most likely to use regular contraception, requesting EC because they missed doses. Reasons older women are not using regular contraception may be attributable to physiological changes such as the menopause, or perceived lack of need after having children. ${ }^{20}$ Trip et al found that younger users may be less likely to use regular contraception due to a lack of ability to find suitable contraception. ${ }^{21}$ Firman et al explored the impact of nature and duration of relationship on preferred method of contraception and established that barrier methods were higher in shortterm relationships among younger population. ${ }^{22}$ Pregnancy 'risk' perception and personal invulnerability may be potential factors influencing the use/non-use of contraception during sexual intercourse. ${ }^{23}{ }^{24} \mathrm{~A}$ large study among young people in Britain aged 16-24 years highlighted the need for more information on 'safer' sex, contraception/birth control, correct condom uses and sexually transmitted infection. ${ }^{25}$ Geary et al reported that young people favour obtaining sexual information and contraception from a healthcare rather than an online source. ${ }^{26}$ Findings of this study support the expressed need for improved sex education in schools alongside greater involvement from healthcare professionals to raise awareness on contraception use.

This is the largest ever study of CP-provided EC services and the first to examine changes in service use over time. The study size and duration mean our results are likely to be generalisable. Restrictions on information recorded in consultations (including data format) and tracing missing information were limitations of this study. However, we accounted for the small number of consultations missing information on age of users and hence it is unlikely that this affects the results. A degree of self-reporting bias from some service users should be considered due to the sensitivity of the topic. The inability to identify repeat EC service users prevented quantification of the actual number of women using the EC service and investigation of changes in contraceptive behaviour over time. Data linkage to enable anonymised identification of multiple consultations by service users should be considered to improve future analyses.

This study suggests improved access to EC, as part of the multifaceted approach set out in Wales' sexual health action plan of $2010,{ }^{27}$ is contributing to a positive and sustained effect towards the root causes of teenage pregnancy. The finding that provision of further sexual health and contraception counselling by pharmacists increased over the study period, in line with the original aims of the EC service, adds further support for extending the role of CPs. Our findings support $\mathrm{CP}$ extended roles, for example in the provision of routine oral contraception, as described in the 2017-2018 report on sexual health in Wales, ${ }^{28}$ and reinforced by Parsons et $a l^{29}$ and the results of the third National Survey of Sexual Attitudes and Lifestyles. ${ }^{30}$

Contributors $\mathrm{EM}, \mathrm{KH}, \mathrm{AE}$ and $\mathrm{CW}$ contributed to the planning of the work reported. AE contributed to obtaining the data. SA and $\mathrm{RH}$ completed the initial analysis and interpretation of the data. EM and $\mathrm{KH}$ supervised the initial analysis and completed further analysis and interpretation of the data. EM led the drafting of the initial report. EM, KH, AE, RD, MLH, GH and $\mathrm{CW}$ contributed to discussion and drafting of subsequent drafts of the report.

Funding The authors have not declared a specific grant for this research from any funding agency in the public, commercial or not-for-profit sectors.

Competing interests None declared.

Patient consent for publication Not required.

Provenance and peer review Not commissioned; externally peer reviewed.

Data availability statement Data are available upon reasonable request.

ORCID iD

Efi Mantzourani http://orcid.org/0000-0002-6313-1409

\section{REFERENCES}

1 National Health Service (NHS). NHS Choices. Emergency contraception (morning after pill, IUD), 2017. Available: 
https://www.nhs.uk/Conditions/contraception-guide/Pages/ emergency-contraception.aspx [Accessed 11 Nov 2017].

2 Levonelle-2 for emergency contraception. Drug Ther Bull 2000;38:75-7.

3 Ulipristal - a new emergency contraceptive pill. Drug Ther Bull 2010;48:86-8.

4 Seston EM, Holden K, Cantrill J. Emergency hormonal contraception: the community pharmacy perspective. J Fam Plann Reprod Health Care 2001;27:203-8.

5 Schenk KD. Emergency contraception: lessons learned from the UK. J Fam Plann Reprod Health Care 2003;29:35-40.

6 Welsh Government. Operational selection policy (OSP), 2006-2011, 2013. Available: http://nationalarchives.gov. uk/documents/information-management/osp60-welshgovernment-2006-2011.pdf [Accessed 12 Oct 2017].

7 Welsh Government. Community pharmacy services in Wales, 2015-16, 2016. Available: http://gov.wales/docs/statistics/ 2016/161019-community-pharmacy-services-2015-16-en.pdf [Accessed 12 Oct 2017].

8 Anderson C, Blenkinsopp A. Community pharmacy supply of emergency hormonal contraception: a structured literature review of international evidence. Hum Reprod 2006;21:27284.

9 Gonsalves L, Hindin MJ. Pharmacy provision of sexual and reproductive health commodities to young people: a systematic literature review and synthesis of the evidence. Contraception 2017;95:339-63.

10 Marston C, Melzer H, Majeed A. Impact on contraceptive practice of making emergency hormonal contraception available over the counter in Great Britain: repeated cross sectional surveys. Obstet Gynecol 2005;106:1102-3.

11 Black KI, Mercer CH, Kubba A, et al. Provision of emergency contraception: a pilot study comparing access through pharmacies and clinical settings. Contraception 2008;77:1815.

12 Black KI, Geary R, French R, et al. Trends in the use of emergency contraception in Britain: evidence from the second and third National Surveys of Sexual Attitudes and Lifestyles. BJOG 2016;123:1600-7.

13 Benchimol EI, Smeeth L, Guttmann A, et al. The reporting of studies conducted using observational routinely-collected health data (RECORD) statement. PLoS Med 2015;12:e1001885.

14 General Medical Council. Using and disclosing patient information for secondary purposes, 2017. Available: https:// www.gmc-uk.org/guidance/ethical_guidance/30614.asp [Accessed 18 Dec 2017].

15 Office for National Statistics. Population estimates, 20112017. Available: https://www.ons.gov.uk/peoplepopulation andcommunity/populationandmigration/populationestimates [Accessed 19 May 2018].

16 Department of Health. Abortion statistics, England and Wales, 2013-2018. Available: https://www.gov.uk/government/ collections/abortion-statistics-for-england-and-wales [Accessed 16 Jul 2018].

17 Births in Wales 2006 - 2016. Data from the National Community Child Health Database, 2017. Available: https:// gov.wales/docs/statistics/2017/170816-births-2016-datanational-community-child-health-database-en.pdf [Accessed 19 Jul 2018].

18 Atkins DN. Association between increased availability of emergency contraceptive pills and the sexual and contraceptive behaviors of women. J Public Health Policy 2014;35:292-310.

19 Aslam Rabeea'h W., Hendry M, Booth A, et al. Intervention now to eliminate repeat unintended pregnancy in teenagers (INTERUPT): a systematic review of intervention effectiveness and cost-effectiveness, and qualitative and realist synthesis of implementation factors and user engagement. BMC Med 2017;15:155.

20 Gerval M, Panay N, Briggs P. Contraception in the 50-somethings. In: Briggs P, Kovacs G, Guillebaud J, eds. Contraception: a casebook from menarche to menopause. Cambridge: Cambridge University Press, 2013: 120-30.

21 Tripp J, Viner R. Sexual health, contraception, and teenage pregnancy. BMJ 2005;330:590-3.

22 Firman N, Palmer MJ, Timæus IM, et al. Contraceptive method use among women and its association with age, relationship status and duration: findings from the third British National Survey of Sexual Attitudes and Lifestyles (Natsal-3). BMJ Sex Reprod Health 2018;44:165-74.

23 Brown S, Guthrie K. Why don't teenagers use contraception? A qualitative interview study. Eur J Contracept Reprod Health Care 2010;15:197-204.

24 Free C, Ogden J. Young women's accounts of factors influencing their use and non-use of emergency contraception: in-depth interview study. BMJ 2002;325:1393 https://www. ncbi.nlm.nih.gov/pmc/articles/PMC138517/

25 Tanton C, Jones KG, Macdowall W, et al. Patterns and trends in sources of information about sex among young people in Britain: evidence from three National Surveys of Sexual Attitudes and Lifestyles. BMJ Open 2015;5:e007834.

26 Geary RS, Tommes C, Jones K, et al. Actual and preferred sources of contraception among young people in Britain: findings from the third National Survey of Sexual Attitudes and Lifestyles (Natsal-3). BMJ Open 2016;6:e011966.

27 Welsh Government. Sexual health and wellbeing action plan for Wales, 2010-2015. Available: http://www.wales.nhs.uk/ sites3/documents/485/Strategy\%20(English)1.pdf [Accessed 16 Jul 2018].

28 Public Heatlh Wales. A review of sexual health in Wales - final report, 2018. Available: http://www.wales.nhs.uk/sitesplus/ documents/888/A\%20Review\%20of\%20Sexual\%20Health\% 20in\%20Wales\%20-\%20Final\%20Report.pdf [Accessed 10 Oct 2018].

29 Parsons J, Adams C, Aziz N, et al. Evaluation of a community pharmacy delivered oral contraception service. J Fam Plann Reprod Health Care 2013;39:97-101.

30 French RS, Geary R, Jones K, et al. Where do women and men in Britain obtain contraception? Findings from the third National Survey of Sexual Attitudes and Lifestyles (Natsal-3). BMJ Sex Reprod Health 2018;44:16-26. 